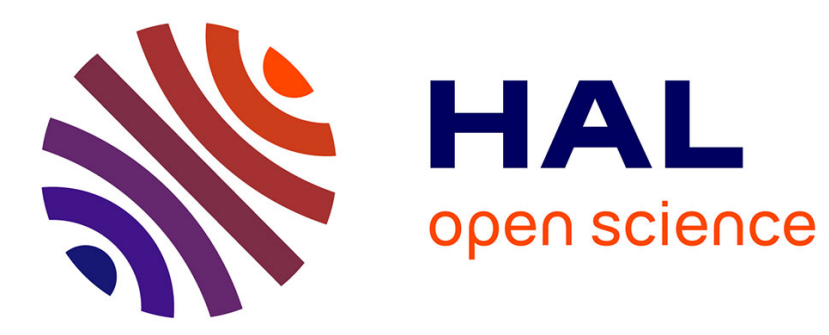

\title{
Experimental and numerical analysis of thermal striping in automotive brake discs
}

\author{
L Augustins, Francois Hild, R Billardon, S Boudevin
}

\section{To cite this version:}

L Augustins, Francois Hild, R Billardon, S Boudevin. Experimental and numerical analysis of thermal striping in automotive brake discs. Fatigue and Fracture of Engineering Materials and Structures, 2017, 40 (2), pp.267-276. 10.1111/ffe.12495 . hal-01481782

\section{HAL Id: hal-01481782 \\ https://hal.science/hal-01481782}

Submitted on 2 Mar 2017

HAL is a multi-disciplinary open access archive for the deposit and dissemination of scientific research documents, whether they are published or not. The documents may come from teaching and research institutions in France or abroad, or from public or private research centers.
L'archive ouverte pluridisciplinaire HAL, est destinée au dépôt et à la diffusion de documents scientifiques de niveau recherche, publiés ou non, émanant des établissements d'enseignement et de recherche français ou étrangers, des laboratoires publics ou privés. 


\title{
Experimental and numerical analysis of thermal striping in automotive brake discs
}

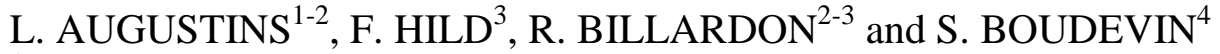 \\ ${ }^{1}$ PSA Peugeot Citroën, Route de Gisy, 78943 Velizy-Villacoublay Cedex, France \\ ${ }^{2}$ now at Messier-Bugatti-Dowty, Innovel Parc Sud, 7 rue Général Valérie André, 78140 Velizy-Villacoublay, France \\ ${ }^{3}$ LMT Cachan, ENS Cachan/CNRS/Université Paris-Saclay, 61 avenue du Président Wilson, 94230 Cachan, France \\ ${ }^{4}$ PSA Peugeot Citroën, 25420 Voujeaucourt, France
}

Correspondence: Louis Augustins.E-mail: louis.augustins@safranmbd.com

\begin{abstract}
In the present study, thermal striping development on friction bands of brake discs is investigated through an experimental and numerical analysis. A test consisting of a series of several hundred severe brakings was carried out on a specific bench at PSA Peugeot Citroën. The experimental observations of the crack network evolution and a numerical analysis of a brake disc with a single crack helped to propose a macroscopic criterion capable of predicting the criticality of the network, namely, its ability to lead to the complete failure of the structure. In addition, a numerical analysis of the crack shielding process is developed whose results are compared with experimental findings.
\end{abstract}

Keywords Thermal striping; automotive brake discs; shielding process.

\section{NOMENCLATURE}

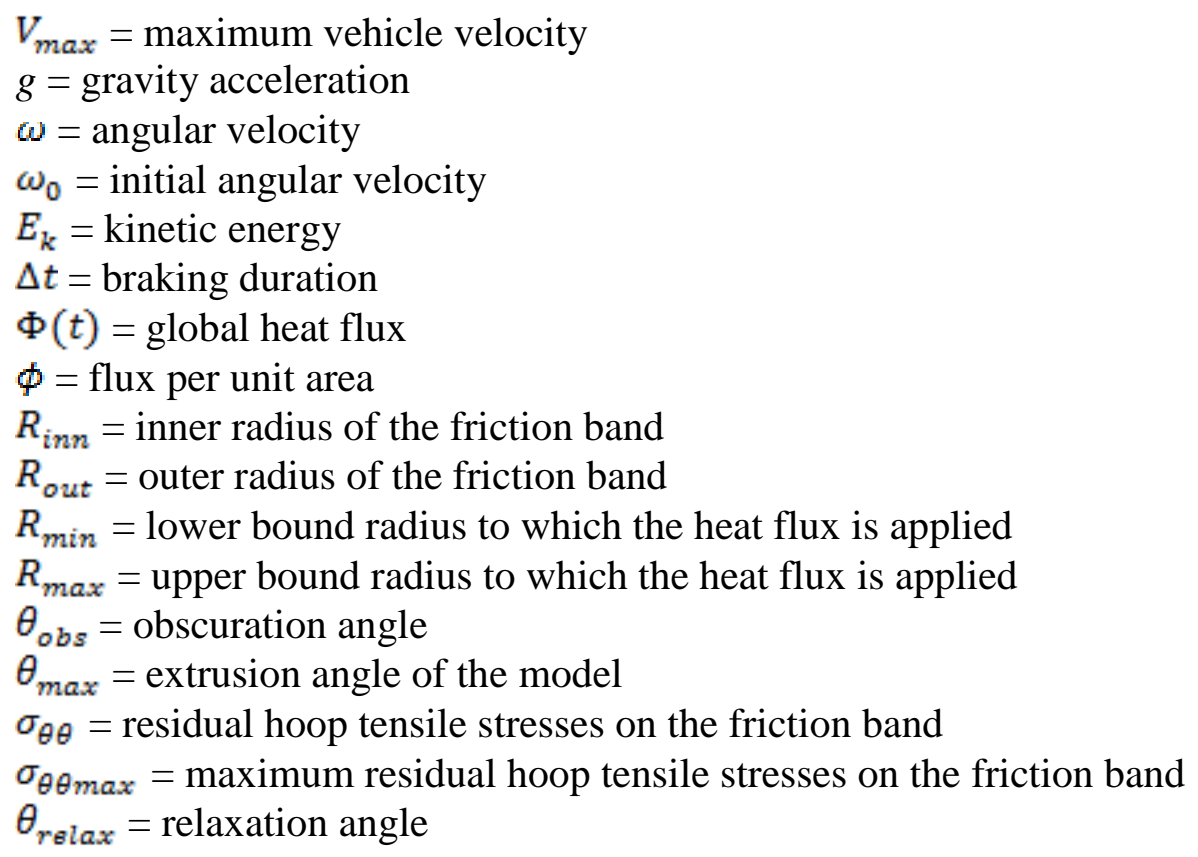




\section{INTRODUCTION}

Thermal fatigue ${ }^{1}$ is characterized by high temperature gradients that prevent free expansion and induce fatigue cracks. In such cases, a crack network appears, often called thermal striping or heat checking. This type of damage is commonly encountered in industrial structures such as molds for metal forming ${ }^{2-4}$, automotive ${ }^{5}$ and railway vehicles ${ }^{6}$ brake discs, or pipes of the cooling systems in nuclear power plants ${ }^{7,8}$.

The crack network appears more or less rapidly, depending on the stress level, but once initiated, crack propagation can be very slow before the failure of the structure or may even stop under certain conditions related to the stress field shape ${ }^{7}$.

The present work focuses on an experimental and numerical analysis of a crack network located on the friction bands of an automotive brake disc made of flake graphite (gray) cast iron $^{9,10}$. On bench tests and even in particular real conditions, a crack network in the form of radial cracks may appear after a low number of brakings without necessarily propagating toward the outer or inner radii or resulting in complete disc failure. Therefore being able to estimate crack initiation through classical low cycle fatigue criteria is not sufficient for an efficient design. It is necessary to estimate the criticality of the network, namely, its likelyhood to result in through thickness radial cracks on the friction ring ${ }^{11}$.

In order to study the evolution of the network, a test campaign on a dynamometric bench, which is appropriate for simulating any braking condition, was carried out at PSA Peugeot Citroën. Based on the analysis of the results, a numerical approach is proposed to assess the criticality of the network.

\section{THEORETICAL APPROACHES}

Early studies devoted to the analysis of thermal striping were developed in the field of metal forming, where molds are subjected to alternate heating and cooling conditions. Cracks are mostly treated independently, estimating initiation from dissipative mechanical variables - such as plastic strain amplitude - and simulating mode I propagation with Linear Elastic (LEFM) or Non-Linear (NLFM) Fracture Mechanics laws ${ }^{2}$. Authors generally agree that an increase in stress level results in an intensification of the crack network density and a decrease in the distance between cracks $^{12}$.

More recent studies ${ }^{13,7,8,14}$ are connected with an incident that occurred in 1998 in the Civaux nuclear power plant ${ }^{15}$ where observations revealed the presence of thermal striping on the internal part of pipes of the cooling system. Their purpose was to improve the understanding of the failure and to develop efficient tools to simulate the evolution and criticality of a crack network. Based on Seyedi et al. work ${ }^{7}$, Malésys et al. ${ }^{8}$ proposed a probabilistic model suitable for describing initiation and cyclic change of crack networks using two main assumptions:

- Continuous formation of cracks, where microcracks develop into mesocracks in the course of time but not all at the same time;

- Crack obscuration or shielding, which characterizes the presence of stress relaxation zones around the cracks. Consequently, the latter ones cannot propagate any farther.

The shielding phenomenon is of critical importance for understanding the partition between arrested and propagating cracks, and the model - using LEFM - gives access to the information about the possible saturation of the crack network and describes its density. 
In the case of automotive brake discs, the density or the saturation of the crack network is not the major issue. The design must avoid through thickness cracks that would result in a complete brake disc failure. Considering a single crack and using LEFM or NLFM to simulate propagation could only give access to qualitative results because of the strong nonlinear behavior of the material ${ }^{9,10}$ for the given loadings in this zone. It is therefore necessary to define engineering indicators that enable the criticality of the crack network to be assessed, namely, its ability to propagate or stop in the radial and through-thickness directions.

\section{EXPERIMENTAL CAMPAIGN}

\section{Experimental set-up}

The disc used in this study is a large ventilated model $330 \mathrm{~mm}$ in diameter (denoted D330) mounted on a heavy vehicle. Each friction band is $10 \mathrm{~mm}$ deep. A series of severe brakings (i.e. deceleration from $80 \% V_{\max }$ to $40 \% V_{\max }$ at $0.5 \mathrm{~g}$ ) was carried out on the dynamometric bench shown in Figure 1, which is composed of an electrical engine and weights representing the vehicle inertia on its rotation axle. The caliper is a fixed part and the deceleration can reach $1.2 \mathrm{~g}$. Every 100 brakings, the crack network is revealed with dye penetrant and pictures are taken. Brake pads are changed every 600 brakings.

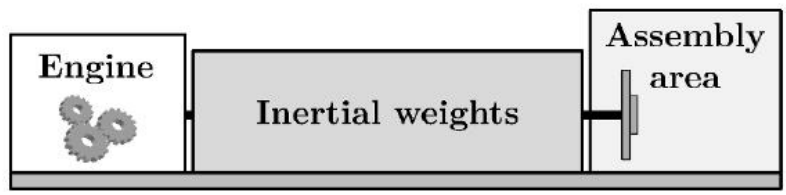

(a)

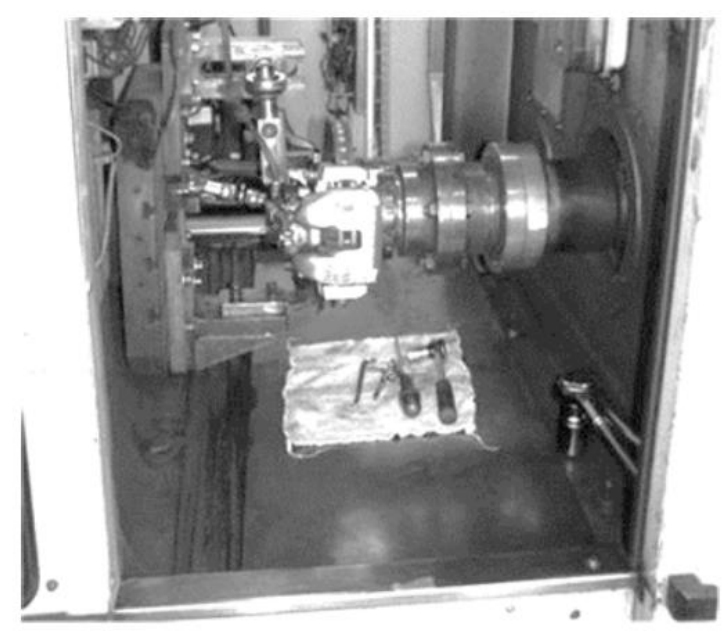

(b)

Fig. 1: Dynamometric test bench. (a) Schematic view; (b) assembly area

In order to accurately simulate the thermal behavior of the disc during braking, thermocouples were utilized (Figure 2a) on a disc on which several brakings were carried out in the desired configuration. Temperature records are shown in Figures $2 \mathrm{~b}$ and $2 \mathrm{c}$. On the external friction band, temperature measurements are essentially steady for successive brakings (Figure 2b) with changes of a few tens of degrees near the outer radius. Conversely, on the internal friction band, temperature measurements are not steady (Figure 2c) and fluctuations can reach $100{ }^{\circ} \mathrm{C}$ and the maximum temperature is not measured on the same thermocouple for successive brakings. This phenomenon is probably due to a high geometrical concentration of heat flux and hot band phenomena ${ }^{16,17}$, which disrupt the stationary response. Because of this uncertainty about 
the heat flux distribution on the internal friction band, observations and thermal simulations focus on the external friction band, for which correlations between numerical models and experimental results are more relevant.

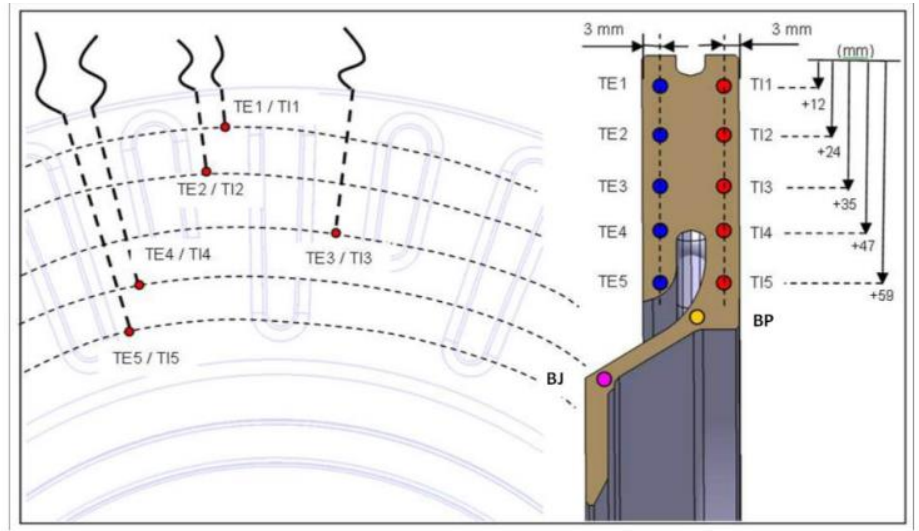

(a)

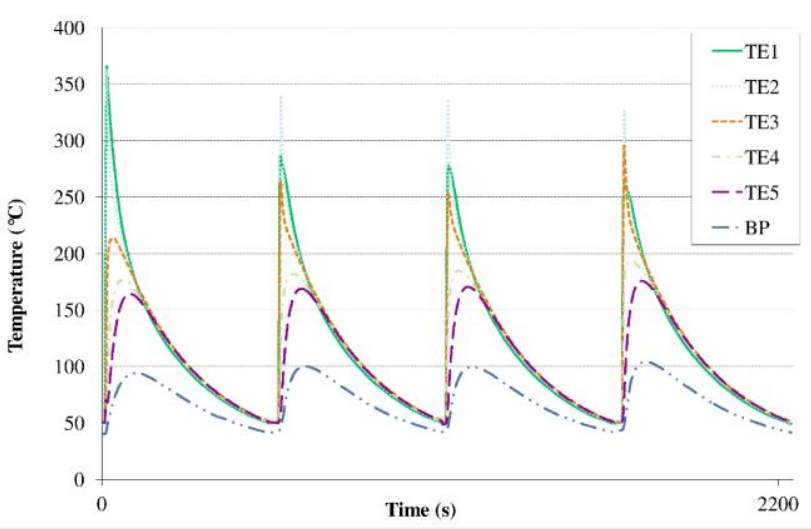

(b)

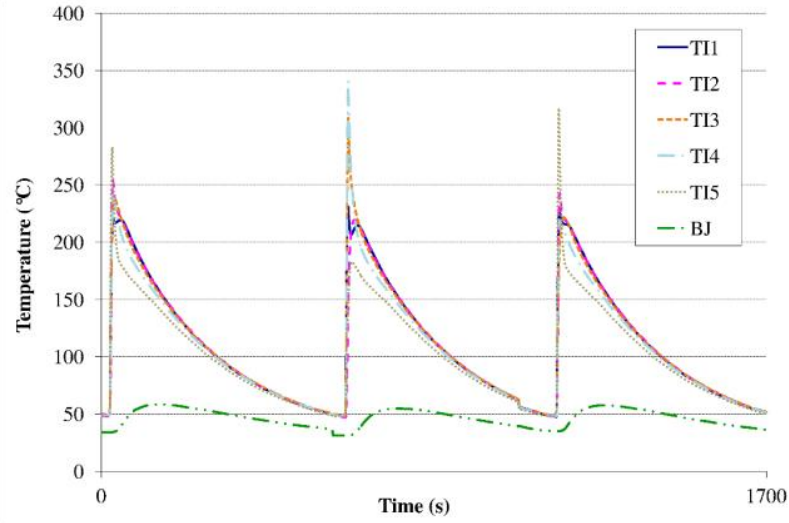

(c)

Fig. 2: (a) Thermocouple implementation and measured temperature history; (b) External friction band; (c) Internal friction band

\section{Crack network evolution}

Figures 3 and 4 show pictures taken after dye penetration on the external friction band for 200 to 500 brakings and for 600 to 2,400 brakings, respectively. A crack network development is observed after 200 to 400 brakings in the area located between radius $R_{\min }$ (near the inner radius) and $R_{\max }$ (near the outer radius). From 500 brakings onward (Figure 3(d)), $R_{\min }$ tends to move toward the inner radius and a second crack network appears in this region, superimposed on the first one. After 600 brakings (Figure 4), this second network becomes more visible. 


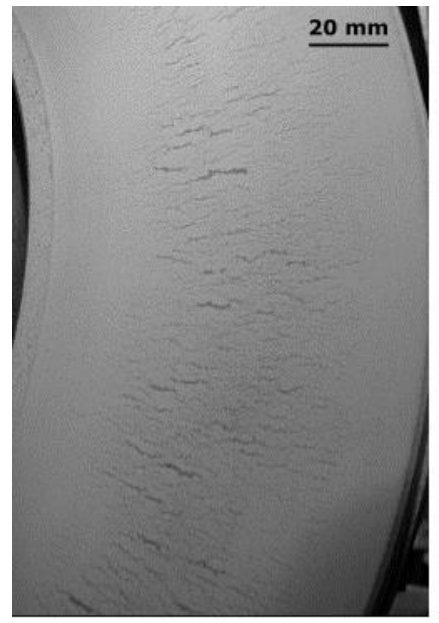

(a)

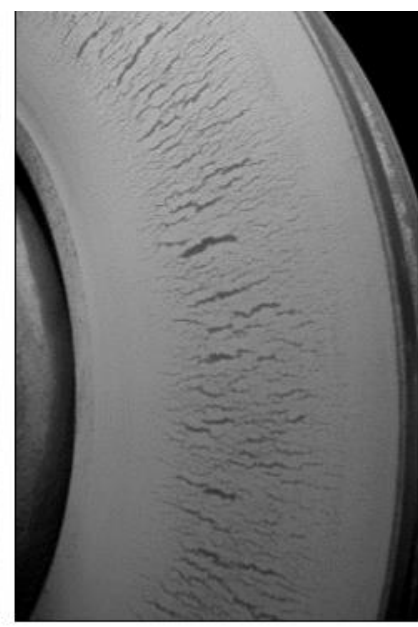

(b)

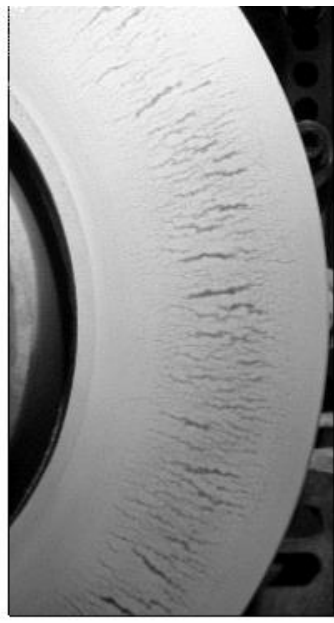

(c)

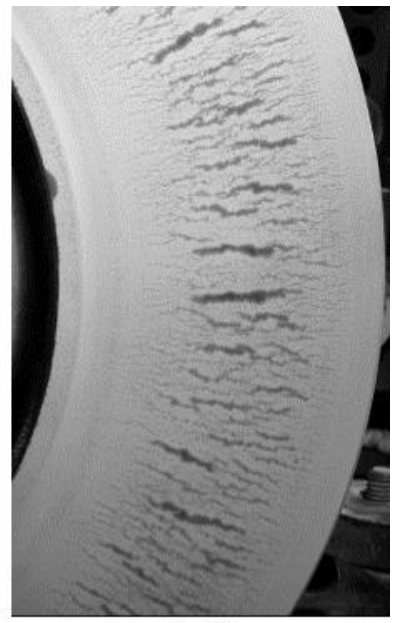

(d)

Fig. 3: Pictures of the external friction band from 200 to 500 brakings

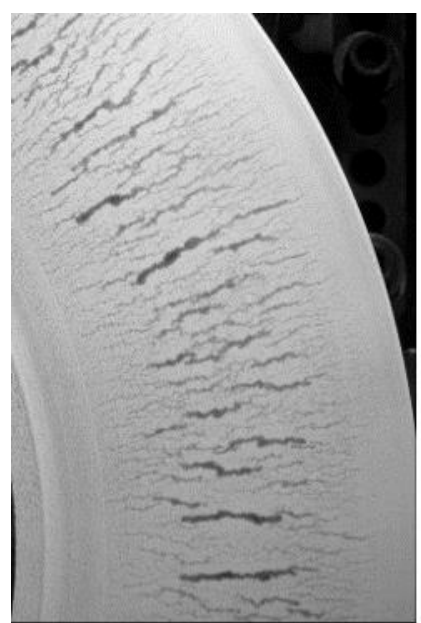

(a)

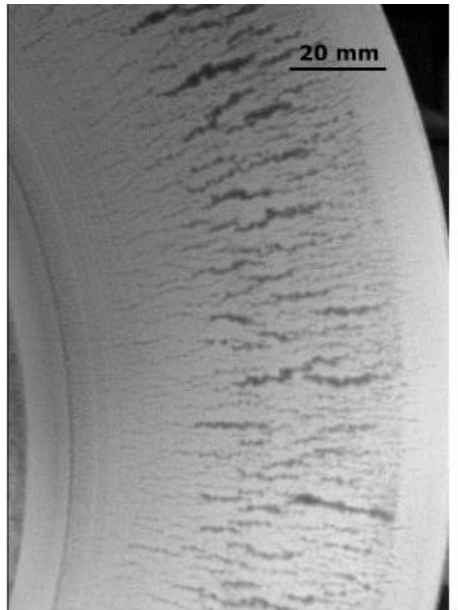

(b)

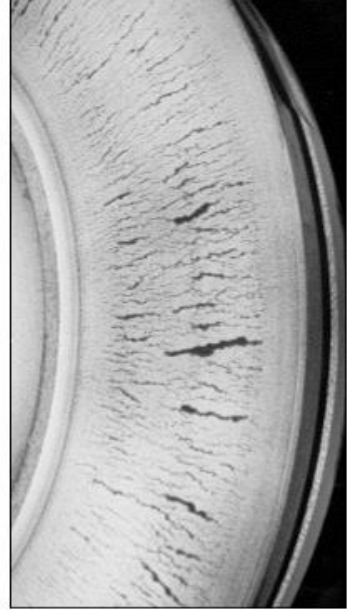

(c)

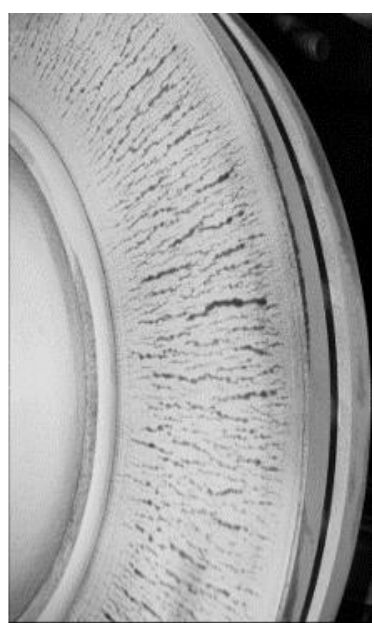

(d)

Fig. 4: Pictures of the external friction band from 600 to 2,400 brakings

This phenomenon can be explained by nonuniform wear of the friction pad. Figure 5 shows the wear profile of the external friction pad after 300 and 600 brakings. The incoming torque area corresponds to that which is first in contact with a point on the disc during a wheel rotation. The z-axis variable relates to the difference between the thickness measured at a particular point and the minimum thickness measured on the whole surface. The lower the value, the higher the wear, namely, a 0-value relates to the area where wear is highest. After 300 brakings (Figure 5(a)), wear is much higher on the outer radius than on the inner one, which is consistent with the flux distribution and the damaged area. After 600 brakings (Figure 5(b)), wear is more uniformly distributed, which is meaning that the flux presents a similar distribution in the radial direction. As a result, a flux appears near the inner radius and gives rise to a second crack network in that area. As friction pads are replaced every 600 brakings, it is reasonable to assume that the phenomenon will repeat itself, namely, a heat flux concentrated in the outer radius area, which mainly acts on the first network and then becomes more uniform and less intense. This phenomenon is illustrated in Figure 6a. 
Between 1,200 and 2,400 brakings, the crack network does not evolve significantly in the radial direction, i.e. $R_{\min }$ and $R_{\max }$ remain unchanged. The crack density is also stable but the diffuse network of the early cycles changes to a more organized one where long cracks propagate and stop the shorter ones. This shielding process is clearly observed in Figure $6 \mathrm{~b}$ and $6 \mathrm{c}$ after 3,200 brakings.

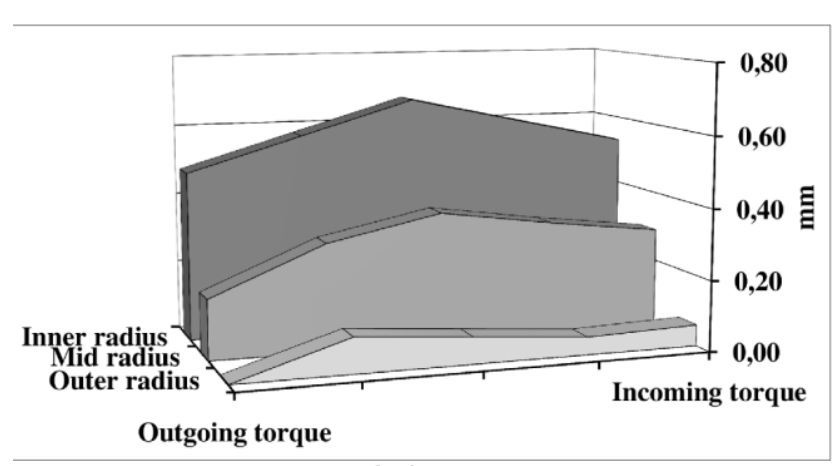

(a)

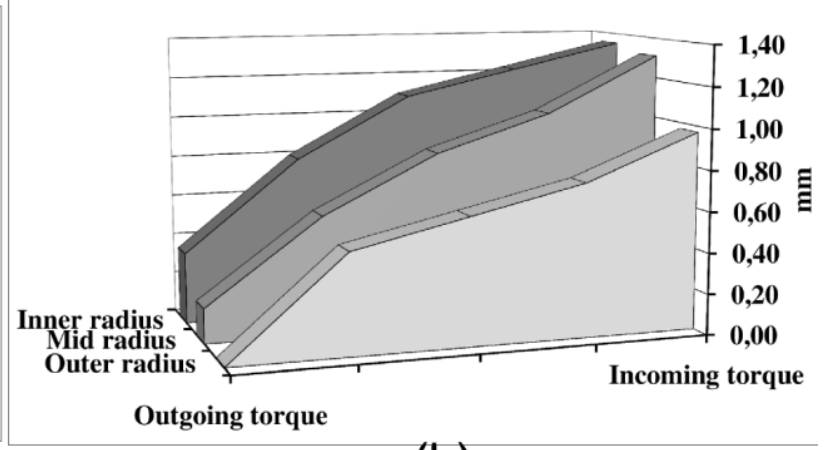

(b)

Fig. 5: External friction pad wear profile after two different numbers of brakings
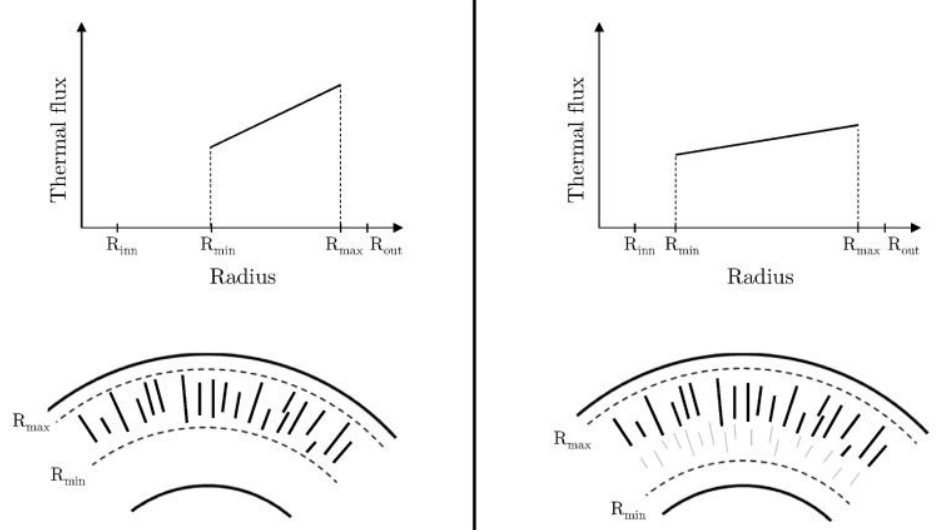

After 300 brakings

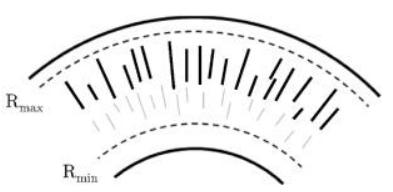

After 600 brakings

(a)

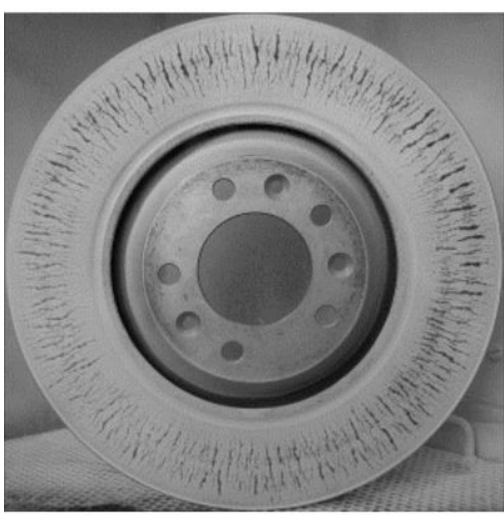

(b)

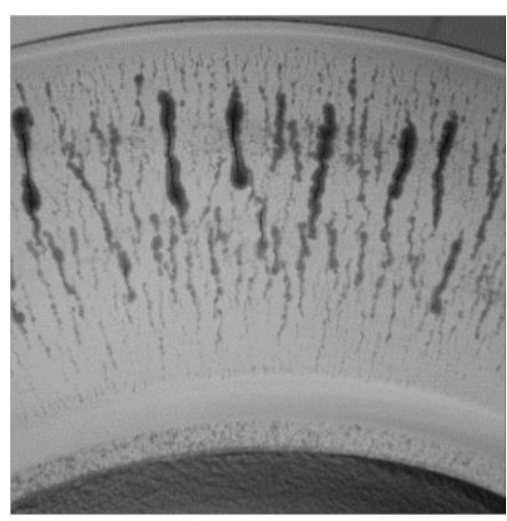

(c)

Fig. 6: (a) Schematic representation of the second crack network formation and thermal striping after 3.200 brakings. (b) Entire disc; (c) zoom on the friction band 
The test was finally interrupted after 3.200 brakings when visual observations showed that cracks no longer evolved in the radial direction or only very slowly. Non-destructive depth measurements were carried out on several long cracks with a crack depth meter RMG $4015^{18}$ using the principle of potential drop measurements between both sides of the crack. Data relating to the longest crack on the external friction band are shown in Figure 7. In view of the semielliptical profile observed on all measurements, the crack depth is approximated with an elliptical shape.

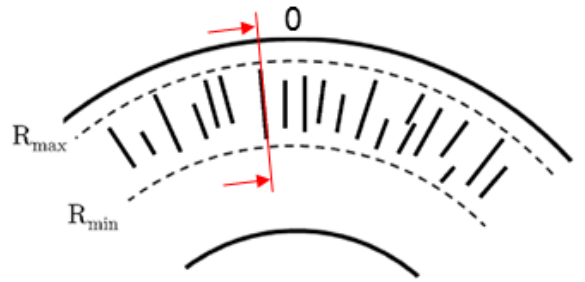

(a)

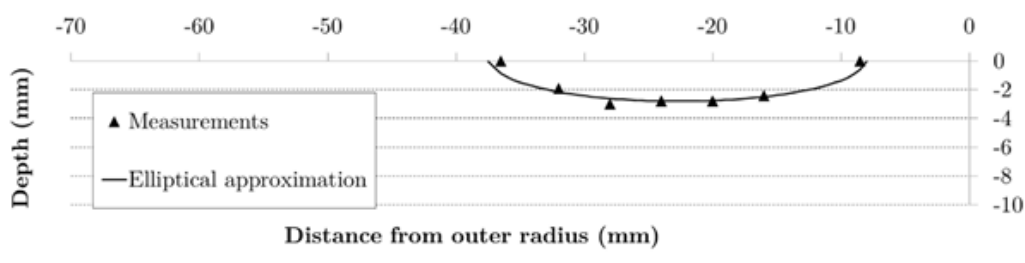

(b)

Fig. 7: Depth measurement of the longest crack on the external friction band and its elliptical approximation. (a) Location of the considred section. (b) Measured crack front

\section{THERMAL STRIPING SIMULATION}

A precise thermo-mechanical simulation of the experimental braking configuration is carried out with the commercial FE code Abaqus. As described in the previous section, the thermal flux gradually evolves during the cycles. However, as temperatures are only recorded for the first cycles, and taking into account the fact that the heat flux is more concentrated and more intense during the first 300 brakings of brake pads life, the simulation of the heat flux is restricted to this time interval. Only an angular sector of the disc is used for the simulations. Adiabatic, cyclic and symmetric boundary conditions are applied to the lateral faces for the thermal and mechanical simulations, respectively. The mesh is composed of 10-node tetrahedra as shown in Figure 8.

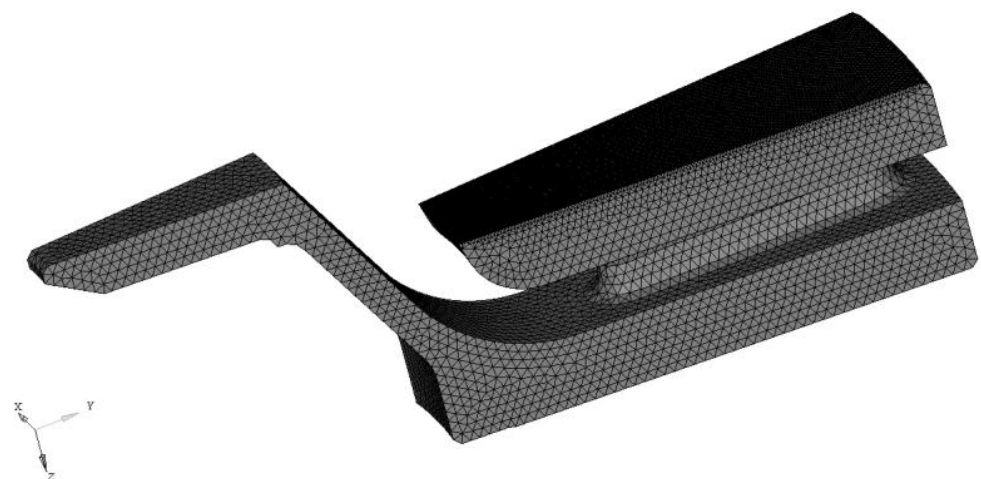

Fig. 8: Mesh of an angular sector of $D 330$ brake disc

\section{Thermal loading}

A test bench with inertia $/$ spinning with an initial velocity $\omega_{0}$ is considered, on which braking with constant deceleration (i.e. the speed decreases linearly with time during braking) is carried 
out several times. Thus, if $\Delta t$ is the braking duration, the angular velocity $\omega$ at time $t$ reads

$$
\omega(t)=\omega_{0}\left(1-\frac{t}{\Delta t}\right)
$$

The kinetic energy is then deduced at time $t$

$$
E_{k}(t)=\frac{1}{2} J \omega(t)^{2}=\frac{1}{2} J \omega_{0}^{2}\left(1-\frac{t}{\Delta t}\right)^{2}
$$

The assumption is that all the kinetic energy is converted into heat and that $95 \%$ of the latter is transmitted to the disc, while the remaining 5\% is transmitted to the linings. The global heat flux $\Phi$ transmitted to the disc is then equal to the derivative of the kinetic energy with respect to time, weighted by a factor $\rho=0.95$. The expression of the global heat flux as a function of time $t$ then reads

$$
\Phi(t)=-\rho \frac{d E_{k}}{d t}=\rho \frac{J \omega_{0} \omega(t)}{\Delta t}
$$

where $R_{\text {in }}$ et $R_{\text {out }}$ are the inner and outer friction surface radii.

Assuming a uniform pressure between the friction pad and the disc, the heat flux per unit area $\phi$ is expressed as a linear function of the radius $r$ and the angular velocity $\omega$

with $A$ a constant.

$$
\phi(r, t)=\operatorname{Ar\omega }(t)
$$

Equations (3) and (4) then give

$$
\int_{R_{\text {inn }}}^{R_{\text {out }}} \int_{0}^{2 \pi} A \omega(t) r^{2} d r d \theta=\rho \frac{J \omega_{0} \omega(t)}{\Delta t}
$$

which leads to the expression of the flux on each of the friction band

$$
\phi(t)=\rho \frac{3 J \omega_{0} r \omega(t)}{4 \pi \Delta t\left(R_{\text {out }}^{\mathrm{s}}-R_{\text {inm }}^{\mathrm{g}}\right)}
$$

This flux can be tuned to correlate thermocouple measurements with simulated data by modifying the inner and outer radii and the value of $A$, keeping the same global flux $\Phi . \phi(r, t)$ then becomes an affine function $\phi(r, t)=(B r+C) \omega(t)$.

Using this type of expression, simulations were carried out to obtain a good correlation with thermocouple measurements on the external friction band (Figure 9). Even if experimental data are not perfectly described (with a maximum error of a few tens of degrees), the orders of magnitude and geometrical localization are faithfully simulated. Given the sources of variability of the temperatures field on the friction bands, this result is deemed satisfactory.

This simulated transient field fits the disc thermal behavior only when new friction pads or friction pads whose wear is fairly low - are taken into consideration, namely, high temperatures are located near the outer radius. It follows that the secondary crack network will presumably not be predicted by the simulation. In the following, the analysis therefore focuses only the primary network near the outer radius. 


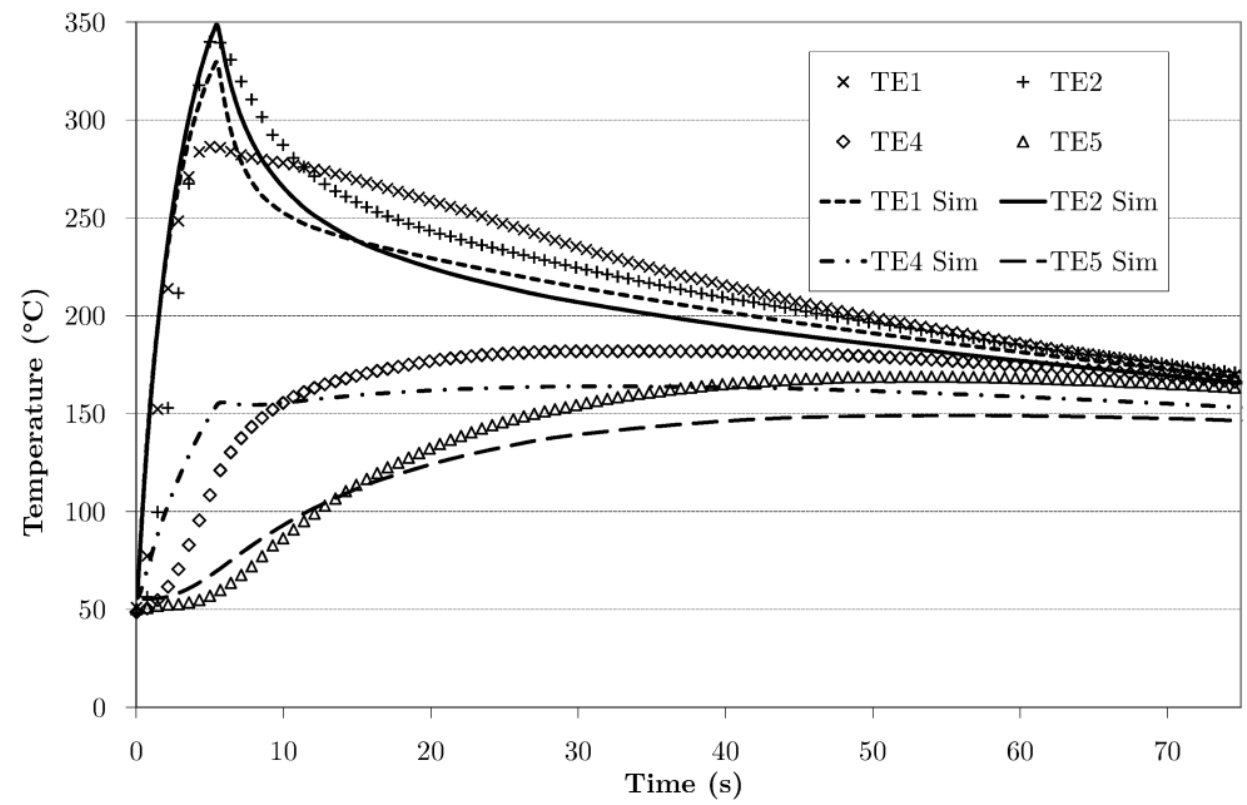

Fig. 9: Correlation between thermal simulation (Sim) and thermocouple measurements on the external friction band

\section{Mechanical field analysis}

Damage mechanisms and stress paths on a brake disc friction band are comprehensively described in Ref. [10]. During braking, the strong through thickness thermal gradient induces high levels of radial and mostly hoop (i.e. orthoradial) compressive stresses, denoted $\sigma_{\theta \theta}$ in a cylindrical basis. Upon cooling, residual tensile stresses following plastic compressive strains appear. Thanks to the thermal simulation and a suitable constitutive model, ${ }^{9,10}$ complete thermomechanical simulations of the braking phases are performed. The residual (positive) hoop stress field in the friction band depth is presented in Figure 10a. It is superimposed to the experimentally observed crack profile, whose shape is similar to the stress contours.

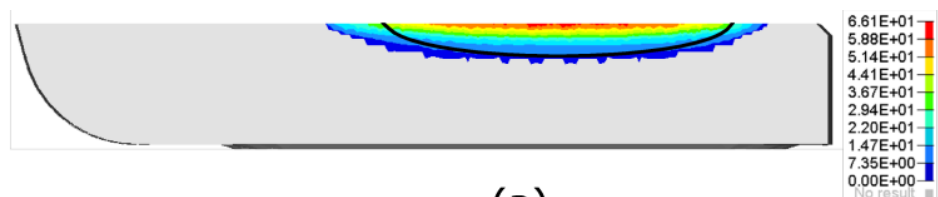

(a)

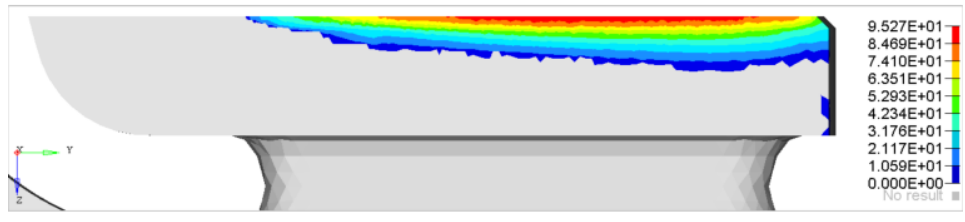

(b)

Fig. 10: (a) Superposition of the experimental crack profile (black solid line) and the simulated residual hoop stresses (in MPa) upon cooling. (a) For the considered test; (b) For a more severe 


\section{Discussion}

The experimental observations show that the crack network has not evolved between 2,400 and 3,200 brakings in the radial direction. In the thickness direction, the crack driving force is the thermal gradient, which becomes very low. It is assumed that the crack does not propagate farther in that direction. The residual hoop stresses can therefore, as a first approximation, be viewed as a boundary beyond which the main cracks of the network do not propagate. In order to support this assumption, a simulation was carried out for a more severe test where a through thickness crack near the outer radius is observed after a few hundred brakings. The residual hoop stresses (Figure 10b) show that the expected boundary reaches the outer radius. This boundary seems to be a relevant indicator of the criticality of the network but strongly depends on the thermal simulation of the braking, which is still a major issue in thermomechanical design of brake discs as many sources of instabilities exist (e.g. thermoelastic instabilities, hot spots, disc and friction band wear).

\section{NUMERICAL ANALYSIS OF THE SHIELDING PROCESS}

The previous section proposed an approach that enables the main crack growth in the radial direction to be predicted. An attempt is made in this section to justify the experimental network morphology in the hoop direction. Figure $6 \mathrm{~b}$ shows an organized and relatively regular crack network where short cracks have been stopped by the shielding zones of the longer ones, according to the mechanism described earlier. ${ }^{7,8}$ Since the total number of main radial cracks can be visually estimated, it is possible to define the average angular spacing in degrees between two

main cracks. This quantity relates to the shielding or obscuration angle $\theta_{\text {obs }}$ of the main cracks and thus to the network pitch. The optical assessment of the number of main cracks depends on the observer and on what is considered to be a main crack, and is necessarily subjective. Bounds are nevertheless defined and the obscuration zone is finally estimated such that $3^{\circ}<\theta_{o b s}<4^{\circ}$. The objective is to predict $\theta_{\text {obs }}$ with a numerical approach and to compare it with the experimental observations. As a first step, it is necessary to identify an area around a crack where hoop stresses are relaxed.

The previous braking simulation must be carried out on an FE model accounting for the crack reported in Figure 7. In order to avoid too long re-meshing and CPU time, a simplified model of the external friction band is used instead of the complete brake disc model. The angular sector is larger than the previous model (i.e. $18^{\circ}$ instead of $10^{\circ}$ ) to avoid side effects and to contain the whole relaxed zone (Figure 11). Details concerning the representativity of the numerical model from a thermal and mechanical point of view are described in Appendix 1. The residual tensile stress $\sigma_{\theta \theta}$ is then plotted as a function of the angle $\theta$ along several radii. For this purpose, post-processing paths are defined on the simplified model (Figure 11). 


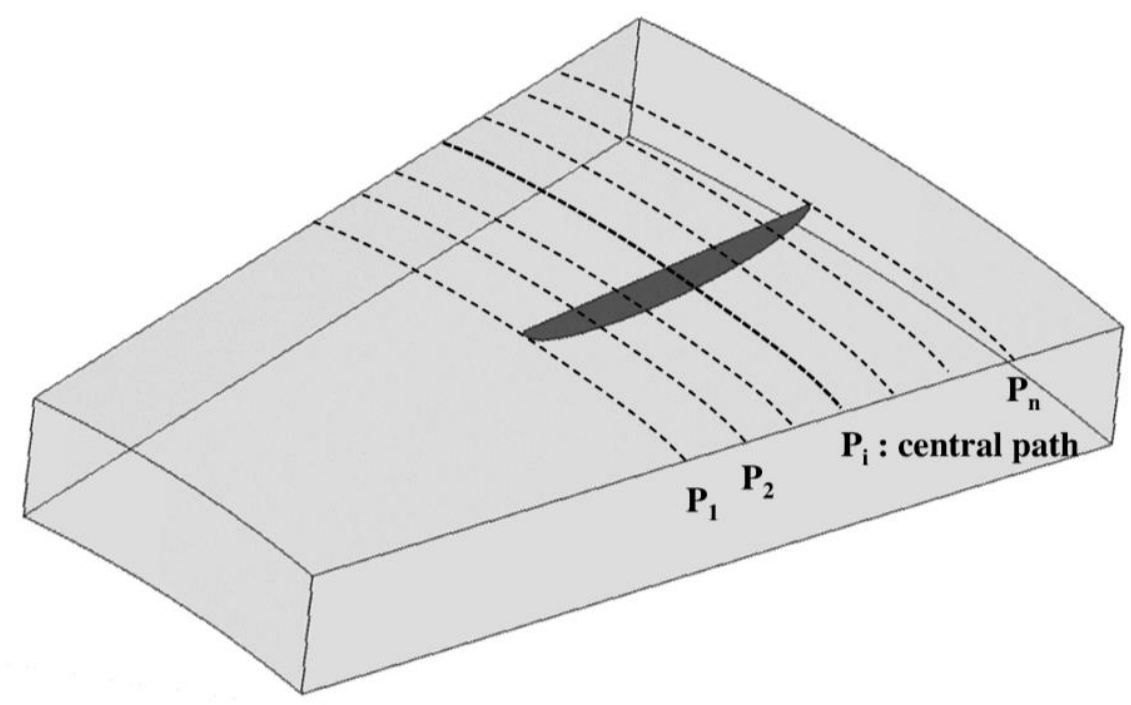

Fig. 11: Simplified model of the external friction band with a crack and associated postprocessing paths $P_{i}$ for the analysis of the relaxation of the hoop stresses

The change of $\sigma_{\theta \theta}$ on the central path (half-way between the radial ends of the crack) is plotted in Figure 12. The stress gradually drops toward 0 near the crack, resulting in a relaxed zone, which is characterized by an angle $\theta_{\text {relax }}$. An upper bound is defined, which corresponds to the angular distance between the $\theta$ values from where the stress begins to differ from its asymptotic value $\sigma_{\theta \theta \max }$. An arbitrary offset needs to be defined in that case. A lower bound is thus preferred. The latter is defined using an idealization of the $\sigma_{\theta \theta}$ profile against $\theta$ with a binary representation, namely, either the stress value is equal $\sigma_{\theta \theta \max }$ or it is null (dotted lines in Figure 12a). The angle $\theta_{\text {relax }}$ is then defined by equivalence between the integral of the real stress along the path and that of the idealized representation

$$
\int_{0}^{\theta_{\max }} \sigma_{\theta \theta} d \theta=\left(\theta_{\max }-\theta_{\text {relax }}\right) \sigma_{\theta \theta \max }
$$

which graphically means that the area of the surface under the dotted lines is equal to that under the solid lines.

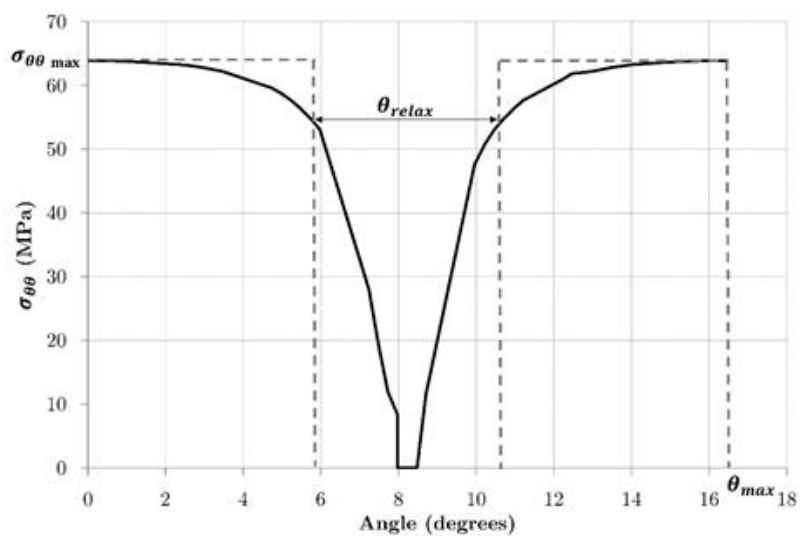

(a)

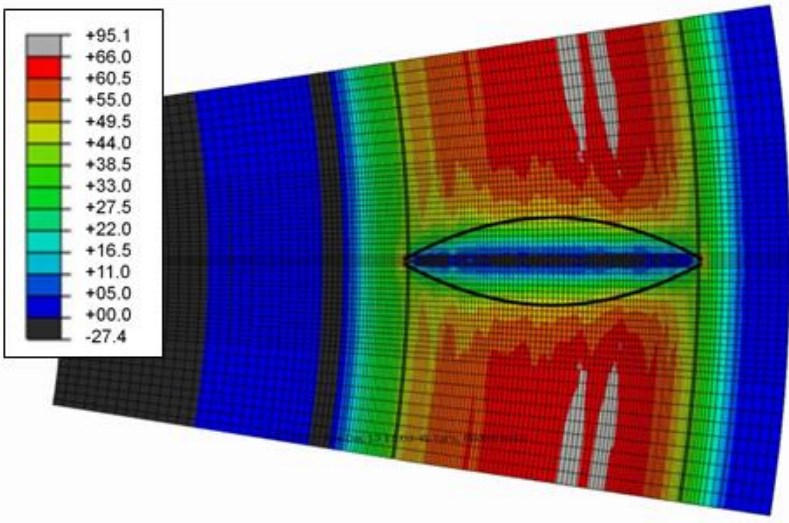

(b)

Fig. 12: (a) $\sigma_{\theta \theta}$ profile on the central path and its idealized representation (dashed lines). (b) $\sigma_{\theta \theta}$ field and idealized relaxation zone (black solid lines) 
A triangular shape is a possible alternative, which is adopted for the study of brittle matrix composites cracking ${ }^{19}$. The estimation of $\theta_{\text {relax }}$ would have been slightly higher. The idealized relaxed zone is plotted in Figure 12b, which is approximated along the radius with a second order polynomial function, superimposed on the residual hoop stress field.

With the chosen idealization, once a crack has formed and propagates, there is an angular domain of width $\pm \theta_{\text {relax }} / 2$ about the crack surface (Figure 12a) in which no new initiation and propagation is possible since the hoop stresses are fully relaxed. With such an assumption $\theta_{\text {relax }}$ corresponds to the minimum angular separation between two macrocracks, i.e., the corresponding relaxation zones should not overlap, Figure 13a). At saturation of the cracking process the maximum angular separation between two macrocracks is equal to $2 \theta_{\text {relax }}$ (Figure $13 b)$.

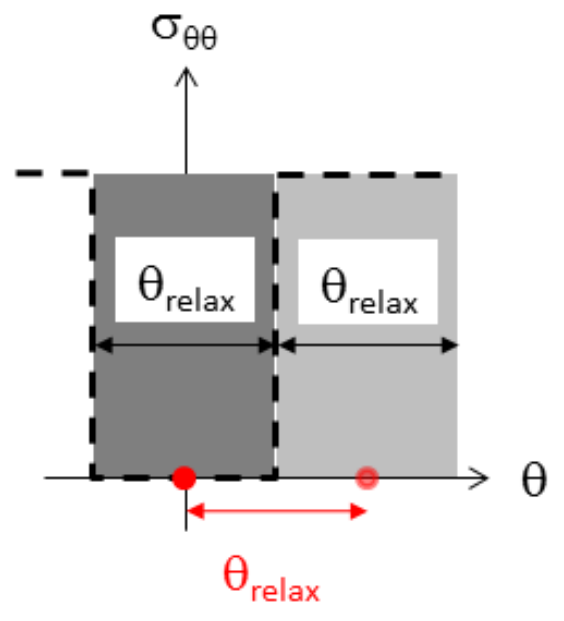

(a)

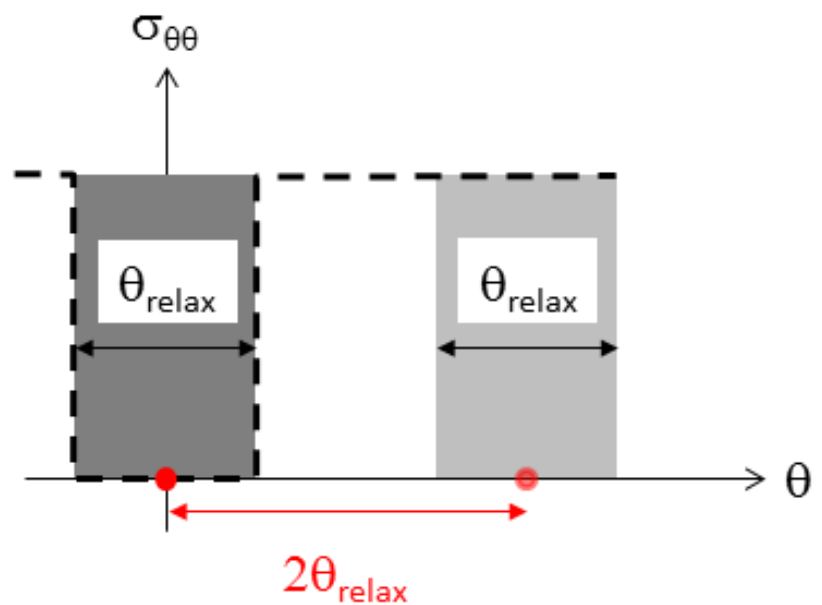

(b)

Fig. 13: Schematic illustration of anglular separations between two neighboring macrocracks (red dots). The stress relaxation zones correspond to the gray shaded areas. Minimum (a) and maximum (b) separation at saturation of macrocracks to avoid any overlap of relaxation zones

Consequently, the minimum separation is not equivalent to the average angular separation. For applications related to particle adsorption, Widom ${ }^{20}$ studied the distribution of $N \delta$-long rigid bars randomly distributed along a line. The author proposed a statistical analysis that is suitable for reaching the average distance $\bar{x}$ between the center of each bar defined by $\bar{x}=1.337 \delta$. Curtin $^{19}$ successfully used an identical approach to predict the average debond length between two cracks in a fragmented monofilament composite in the limit of an infinite Weibull modulus. Analogously, the mean angular separation (or angular pitch) is $\theta_{\text {obs }}=1.337 \theta_{\text {relax }}$ for the crack network. For each considered path (Figure 11) $\theta_{\text {obs }}$ is calculated and the results are reported in Figure 14. 


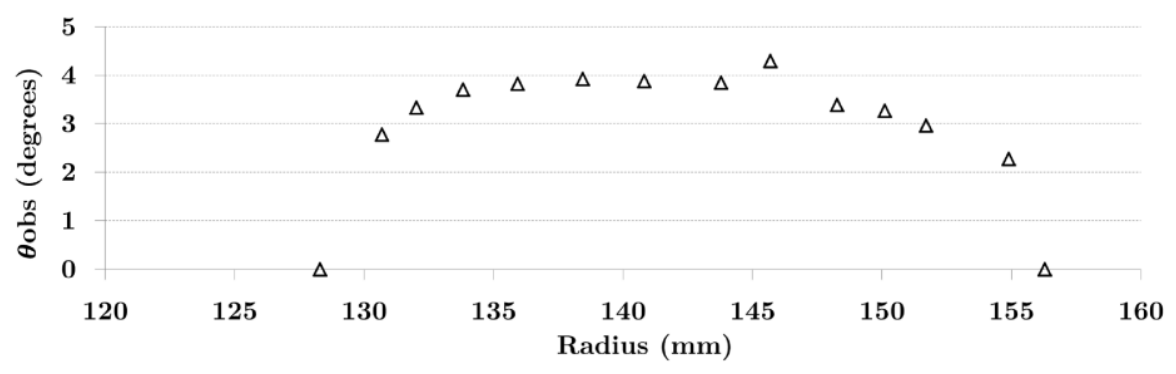

Fig. 14: Obscuration zone angle

The maximum angular separation is $4^{\circ}$, which is to be compared with the visual estimate $3^{\circ}<\theta_{o b s}<4^{\circ}$. There is a good agreement between theoretical values and experimental results, reflecting the consistency of the approach for addressing the development of thermal striping.

\section{CONCLUSION}

The purpose of this paper was to study the propagation of a thermal fatigue crack network on the friction band of an automotive brake disc. The experimental set-up made it possible to carry out more than 3,000 severe consecutive brakings. Observations with dye penetrant revealed a stabilized network that does not lead to the complete failure of the disc.

Numerical thermomechanical simulations of the experimental braking were performed and showed that the residual hoop stresses coincide with the main radial stabilized crack profile. It was concluded that this field represents a boundary beyond which the crack network does not further evolve in the radial and depth directions.

In addition, a numerical analysis on a single crack brake disc model was carried out in order to justify, from a numerical point of view, the observed network shape and its associated angular pattern. Based on the proposed assumptions (i.e. stress relaxation induced by propagating cracks), the latter is satisfactorily predicted by the numerical model.

\section{Acknowledgements}

This work was carried out within the Executive Doctorate in Industry framework, and was supported by PSA Peugeot Citroën. 


\section{REFERENCES}

1. D.-A. Serpa (1976). What is thermal fatigue ? ASTM, 612, 3-9.

2. A. Oudin (2001). Thermo-mechanical fatigue of hot work tool steels. PhD thesis, Ecole Nationale Supérieure des Mines de Paris.

3. A. Persson, S. Hormark, and J. Bergström (2005). Thermal fatigue cracking of surface engineered hot work tool steels. Surf. Coat. Tech., 191, 216-227.

4. A. Srivastava, V. Joshi, and R. Shivpuri (2004). Computer modeling and prediction of thermal fatigue ckacking in die-casting tooling. Wear, 256, 38-43.

5. F. Vallet (1999). Etude de la fissuration d'un disque de frein à partir de l'analyse de son comportement thermomécanique. $\mathrm{PhD}$ thesis, INSA Lyon.

6. G. Degallaix and P. Dufrenoy (2007). Fatigue thermique de disques de frein ferroviaires. In 23emes Journées de Printemps de la SF2M "Fatigue sous Sollicitations Thermiques".

7. M. Seyedi, S. Taheri, and F. Hild (2006). Numerical modeling of crack propagation and shielding effects in a striping network. Nucl. Eng. Des., 236, 954-964.

8. N. Malésys, L. Vincent, and F. Hild (2009). A probabilistic model to predict the formation and propagation of ckack networks in thermal fatigue. Int. J. Fat., 31, 565-574.

9. L. Augustins, R. Billardon, and F. Hild (2015). Constitutive model for flake graphite cast iron automotive brake discs. From macroscopic multiscale models to a $1 \mathrm{D}$ rheological description. Continuum Mech. Therm., Online, DOI 10.1007/s00161-015-0448-z.

10. L. Augustins, R. Billardon, and F. Hild (2015). Constitutive model for flake graphite cast iron automotive brake discs. Induced anisotropic damage model under complex loadings. Continuum Mech. Therm., accepted manuscript.

11. F. Bagnoli, F. Dolce, and M. Bernabei (2009). Thermal fatigue cracks of fire fighting vehicles gray iron brake discs. Eng. Fail. Anal., 16, 152-163.

12. S. Le Roux, F. Medjeboud, G. Dour, and F. Rézaï-Aria (2013). Role of heat-flux density and mechanical loading on the microscopic heat-checking of high temperature tool steels under thermal fatigue experiments. Int. J. Fat., 51, 15-25.

13. V. Maillot, A. Fissolo, G. Degallaix, and S. Degallaix (2005). Thermal fatigue crack networks parameters and stability: an experimental study. Int. J. Solids. Struct., 42, 759-769.

14. J. Rupil, L. Vincent, F. Hild, and S. Roux (2011). Identification and probabilistic modeling of mesocrack initiations in 304L stainless steel. Int. J. Multiscale Com., 9, 445-458.

15. J.-M. Stephan, F. Curtit, C. Vindeirinho, S. Taheri, M. Akamatsu, and C. Peniguel (2002). Evaluation of the risk of damage in mixing zones: EDF R\&D. In Proceedings fatigue, 32, 1707.

16. J. R. Barber (1969). Thermoelastic instabilities in the sliding of conforming solids. In P. R. Soc. London., A312, 381-394.

17. A. L. Cristol, Y. Desplanques, W. Osterle, and G. Degallaix (2010). Coupling between thermal localisation and friction mechanisms: heat accumulation effect. In Proceedings of the 6th European Conference on Braking, 61-69.

18. K. Deutsch (2010). RMG 4015 Crack Depth Measurement. KARL DEUTSCH, www.karldeutsch.de.

19. W. A. Curtin (1991). Exact theory of fiber fragmentation in single-filament composite. J. Mat. Sci., 26, 2837-2845.

20. B. Widom (1966). Random sequential addition of hard spheres to a volume. J. Chem. Phys., 44, 3888-3894. 


\section{APPENDIX 1}

From a heat transfer point of view, merely modeling the external friction ring and applying the same loads and boundary conditions as in the case of the complete model has very little influence on the final response. The only difference lies in the fact that heat is not transmitted through the fin and this results in a slight increase in temperature on the underside of the friction ring. The temperature field at hottest braking time is shown in Figure 15 for the complete and the simplified model with no crack.

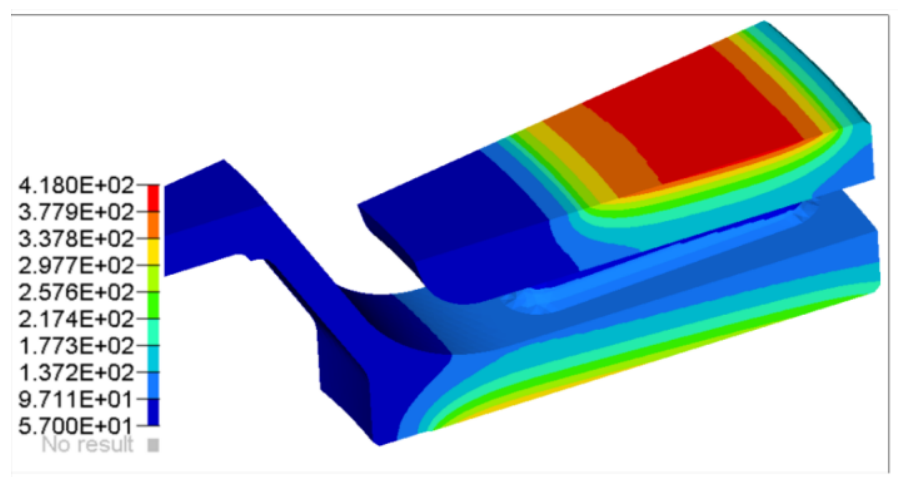

(a)

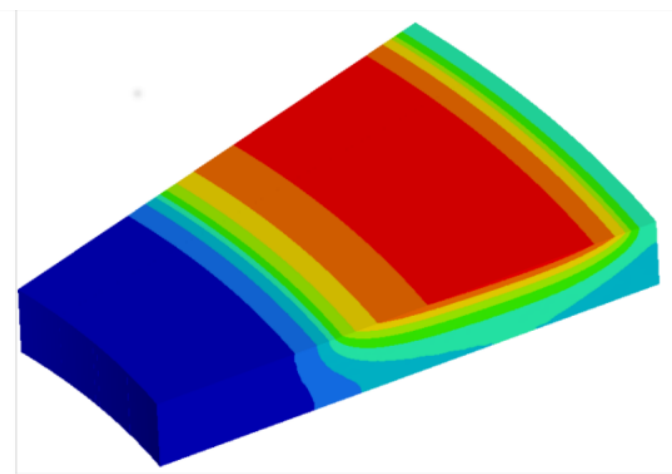

(b)

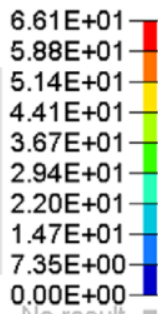

(c)

Fig. 15: Temperature field (in ${ }^{\circ} \mathrm{C}$ ) at hottest braking time. (a) Complete brake disc model; (b) simplified model. (c) Residual hoop stresses field (in MPa) on the simplified mechanical model with no crack

The same mechanical boundary conditions as those applied to the complete disc are applied to the lateral sides of the simplified model. Displacement in the direction corresponding to the thickness of the friction ring is clamped on its underside. The residual (tensile) hoop stress field for the simplified model withno crack is shown in Figure $15 \mathrm{c}$ and presents a profile similar to that obtained with the complete model. 